Article

\title{
Prevalence of Cyberstalking and Previous Offline Victimization in a Sample of Italian University Students
}

\author{
daniela acquadro maran $1, *$ (D) and tatiana begotti ${ }^{2}$ \\ 1 Work and Organisational Well-being Research Group, Department of Psychology, University of Torino, \\ 10124 Torino, Italy \\ 2 Department of Psychology, University of Torino, 10124 Torino, Italy; tatiana.begotti@unito.it \\ * Correspondence: daniela.acquadro@unito.it; Tel.: +39-011-670-2212
}

Received: 28 November 2018; Accepted: 16 January 2019; Published: 21 January 2019

check for updates

\begin{abstract}
Cyberstalking has been defined as the use of electronic communication devices (including the Internet and email) to stalk another person. The aim of this study was to compare the effects of cyberstalking between victims of cyberstalking and victims of cyberstalking and previous offline victimization in their lifetimes. Our hypothesis was that cyberstalking had an impact on victims' wellbeing and contributed to increases in physical and emotional symptoms, anxiety and depression, and that those symptoms increased in victims who had suffered previous offline victimization. In an effort to investigate the effects of cyberstalking, a questionnaire was self-administered to 229 Italian students. A total of 107 participants (46.7\%) indicated that they had been victims of cyberstalking. Seventy-two of them (67.3\%) were victims of both cyberstalking and other forms of offline victimization in their lifetimes. Overall, our findings showed that the prevalence of cyberstalking in our sample was higher than in previous investigations. With regard to consequences, victims indicated higher scores for depression and anxiety than non-victims. In particular, victims of cyberstalking and previous offline victimization in their lifetimes experienced more depression and symptoms of trait anxiety than victims of cyberstalking only and non-victims. This investigation suggests the importance of preventing cyberstalking and offering support to victims of cyberstalking.
\end{abstract}

Keywords: cyberstalking; coping strategies; previous victimization

\section{Introduction}

Cyberstalking has been defined as the use of electronic communication devices to stalk another person (Spitzberg and Hoobler 2002). As argued by Strawhun et al. (2013), the term has been used to refer "to repeated threats or harassment through electronic mail or other computer-based communication that make a reasonable person fear for his or her safety [ ... ] Cyberstalking not only provides more rapid methods of choosing and identifying victims but also has created more subtle ways of constantly terrorizing individuals of all ages, races, genders, faiths, and sexual orientation" (pp. 141-42) (see also Finn 2004). Like stalking, cyberstalking is a phenomenon characterized by intrusive and repeated behaviour with the intent to threaten or harass the victim (De Fazio and Sgarbi 2012; Sheridan and Grant 2007). Consequently, the victim experiences a serious, continual state of anxiety or fear that affects their quality of life and could force him/her to change his/her living habits (Westrup 1998; Acquadro Maran et al. 2017; Acquadro Maran and Varetto 2018). Alexy et al. (2005) argued that the abilities of an online and an offline stalker are similar, as are the impacts on the victim's wellbeing.

Findings from studies conducted on the prevalence of the phenomenon have shown that among college students, cyberstalking is a common behaviour, and it could be an antecedent to face-to-face 
expression of violence (Marganski and Melander 2018). Spitzberg and Hoobler (2002) found that among 235 undergraduate college students, almost one-third reported some form of unwanted online pursuit, while Paullet et al. (2009), in their investigation among 302 undergraduate and graduate students, found that $13 \%$ of the participants were victims of cyberstalking. Similar data were obtained by Kraft and Wang (2010): in their investigation among 471 college students, 9\% of the participants experienced cyberstalking victimization. Victims stated that the main reason that they are targeted is because someone decided to target them (see also Spitzberg and Hoobler 2002). A contributory factor seems to be linked to the confidence placed in the online space, as students often do not exercise the same caution in communicating online with unknown individuals as they would face-to-face interactions (Lyndon et al. 2011; Marcum et al. 2017). They allow themselves to be vulnerable to cyberstalking online, which can place them at risk for stalking in the real world if they post personal information (e.g., last name, address, cell phone number, where they are) without thinking about the consequences (Wright 2018).

With regard to the nature of the victim-perpetrator relationship, previous research reported contradictory results. For example, in a survey by Cavezza and McEwan (2014) among a sample of 36 forensic cyberstalkers, data showed that they were more likely to be ex-intimate partners. In the investigation by Reyns et al. (2012) that involved 355 victims of cyberstalking, findings revealed that perpetrators were most likely to be strangers (42.5\%), while friends/acquaintances comprised $35.8 \%$ of cyberstalkers and intimate partners comprised $21.7 \%$. The behaviour that characterized cyberstalking activity can vary, as suggested by Reyns et al. (2012), who noted identity fraud, unwanted contact, threats of violence, unwanted sexual advances, and harassment among the many forms of cyberstalking activity. D'Ovidio and Doyle (2003) analysed 134 records of cyberstalkers from the New York Police Department's Computer Investigation \& Technology Unit. From their findings, it emerged that in $92 \%$ of the cases the offenders used only one type of behaviour (in $79 \%$ of cases the mode of contact was email). Cyberstalking has consequences on victims' mental health and wellbeing, such as distress (Jansen van Rensburg 2017) and feelings of betrayal, hurt, paranoia, insomnia, anger, fear, anxiety and depression (Cavezza and McEwan 2014; Golladay and Holtfreter 2017; Worsley et al. 2017).

An interesting question pertains to previous victimization, although currently there is a lack of literature regarding the analysis of previous offline victimization and its consequences on online victimization. The experience of offline forms of violence could have an impact on online victimization; for example, the previous victimization could explain the difficulty in the use of effective coping strategies and-as a consequence - the accompanying physical and emotional malaise (Classen et al. 2005). Oksanen and Keipi (2013) in a cross-sectional survey in Finland, found that prior violent victimization (e.g., harassment) was strongly associated with cyber victimization. In an investigation on health care professional victims of stalking, Acquadro Maran and Varetto (2018) found that among 270 self-declared victims, 54\% of them previously experienced violence in their lives. Moreover, in their revision of the literature, Classen et al. (2005) found that two-thirds of individuals who were sexually victimized are at risk of revictimization. Previous victimization had a stronger impact on individuals' physical and emotional wellbeing; when they are revictimized, they show more anxiety, more difficulty in interpersonal relationships, more depression and lower self-esteem than victims who had not experienced previous victimization (Reed et al. 2016).

\section{Current Study and Aim}

In Italy, stalking has been a crime since 2009 (Penal Code, article 612 bis, 2009). The law states the following: "Provided the act is not recognized as a more serious crime, it is a criminal offence, punishable with imprisonment ranging from six months up to four years, to continuously threaten or harass another person to such an extent as to cause a serious, continual state of anxiety or fear, or to instill in the victim(s) a motivated fear for his/her own safety or for the safety of relatives or other persons linked to the victim(s) by virtue of kinship or emotional relationship or to force the victim(s) to change his/her living habits". In the Italian legal system, the online conduct of defamation, identity fraud, and hacking are considered an extension of stalking (Cassano 2017). In Italy, on average 
21.5\% of women (Istat 2016) and 18.7\% of men (Macrì et al. 2012) are victims of stalking. In regard to cyberstalking, an investigation by Manunza et al. (2018) found that among 187 health care professionals, $3 \%$ experienced cyberstalking. However, to the best of our knowledge, there has not been investigation on the prevalence of cyberstalking in Italian university students. Due the lack of information about cyberstalking (e.g., characteristic behaviours, consequences) in this population, we intended first of all to analyse the impact of cyberstalking on victims. Moreover, our aim was to analyse the impact of this phenomenon on victims who had previous offline victimization experiences (e.g., bullying, domestic violence), compared to those who did not have such previous experiences. Our hypothesis was that cyberstalking had an impact on victims' wellbeing and contributed to increases in physical and emotional symptoms, anxiety and depression, and that those symptoms would be greater in victims who had suffered previous victimization.

\section{Results}

The sample included 229 (91.6\%) respondents; 21 questionnaires were not fully completed in most parts of the scales (these questionnaires were excluded from analysis). The majority of respondents $(132,57.6 \%)$ indicated that they spent $1-3 \mathrm{~h}$ on the Internet per day. The use of the Internet was principally indicated as a way to have fun $(225,98.3 \%)$, send messages $(218,95.2 \%)$, chat $(199,86.9 \%)$ and play games $(71,31 \%)$.

A total of 107 participants (46.7\%) indicated that they had been victims of cyberstalking $(61 \%$ females; mean age $=22.7$ years, $S D=1.97)$. Within this sample, $62(57.9 \%)$ experienced more than one type of cyberstalking behaviour. A total of 72 (67.3\%) participants were victims of both cyberstalking and other forms of victimization in their lifetimes, and the remaining portion of these participants were victims of cyberstalking only. Most of the victims were single (65\%), 27.5\% were engaged, and $2.8 \%$ were cohabiting; the remaining individuals did not provide information about their relationship status. To facilitate the presentation of this paper, we have labelled the victims of cyberstalking as VCS, the victims who had experienced cyberstalking and previous offline victimization in their lifetimes as VCSLF, and the subjects who had not experienced cyberstalking as NotVCS.

\subsection{Characteristics of Cyberstalking}

Overall, 64 (27.9\%) participants defined themselves as victims of cyberstalking and reported having suffered cyberstalking through online contacts (see Table 1). Online harassment was experienced by 44 (19.2\%) participants; 46 (20.1\%) participants reported having suffered cyberstalking through unwanted online sexual advances; online threats of violence were experienced by $27(11.8 \%)$ participants; and 28 participants (12.2\%) reported having endured stalking through online identity fraud. A total of $62(57.9 \%)$ victims experienced more than one type of cyberstalking. In most of the cases the victim was a female while the cyberstalker was a male. Moreover, in most cases the cyberstalker was a friend/acquaintance.

Table 1. Characteristic of the cyberstalking campaign $(N=107)$. Values in percentage between brackets.

\begin{tabular}{|c|c|c|c|c|c|}
\hline & $\begin{array}{l}\text { Online } \\
\text { Contacts }\end{array}$ & $\begin{array}{c}\text { Online } \\
\text { Harassment }\end{array}$ & $\begin{array}{l}\text { Online Unwanted } \\
\text { Sexual Advances }\end{array}$ & $\begin{array}{l}\text { Online Threats } \\
\text { of Violence }\end{array}$ & $\begin{array}{c}\text { Online } \\
\text { Identity Fraud }\end{array}$ \\
\hline & $n=64(\%)$ & $n=44(\%)$ & $n=46(\%)$ & $n=27(\%)$ & $n=28(\%)$ \\
\hline \multicolumn{6}{|l|}{ Victims: } \\
\hline Female & $47(73.4)$ & $23(52.3)$ & $34(73.9)$ & $12(44.4)$ & $15(53.6)$ \\
\hline Male & $17(26.6)$ & $21(47.7)$ & $12(26.1)$ & $15(55.6)$ & $13(46.4)$ \\
\hline with previous victimization & $42(65.6)$ & $35(79.5)$ & $34(73.9)$ & $21(77.8)$ & $21(75)$ \\
\hline \multicolumn{6}{|l|}{ Cyberstalker: } \\
\hline Female & $13(20.3)$ & $11(25)$ & $4(8.7)$ & $9(33.3)$ & $4(14.3)$ \\
\hline Male & $35(54.7)$ & $23(52.3)$ & $26(56.5)$ & $12(44.4)$ & $8(28.6)$ \\
\hline \multicolumn{6}{|l|}{ Nature of the relationship: } \\
\hline Ex-partner & $13(20.3)$ & $7(15.9)$ & $2(4.3)$ & $3(11.1)$ & $3(10.7)$ \\
\hline Friends/Acquaintance & $35(54.7)$ & $26(59.1)$ & $28(60.9)$ & $18(66.7)$ & $9(32.11)$ \\
\hline Unknown & $16(25)$ & $11(25)$ & $16(34.8)$ & $6(22.2)$ & $16(57.1)$ \\
\hline
\end{tabular}




\subsection{Physical and Emotional Symptoms in Victims of Cyberstalking}

The victims reported various consequences connected to having experienced cyberstalking. In Table 2, we report the physical and emotional symptoms. Only victims of cyberstalking responded to these questions.

Table 2. Physical and emotional symptoms: comparison between victims of cyberstalking (VCS) and victims who had experienced cyberstalking and previous offline victimization in their lifetimes (VCSLF) $(N=107)$.

\begin{tabular}{ccccc}
\hline & VCS & VCSLF & \multirow{2}{*}{$\chi^{2}$} & $p$ \\
\cline { 2 - 3 } & $n=\mathbf{3 5}(\mathbf{\%})$ & $\boldsymbol{n}=\mathbf{7 2} \mathbf{( \% )}$ & & \\
\hline Physical symptoms: & & & & \\
Weight change & $1(2.9)$ & $10(13.9)$ & 2.56 & n.s. \\
Appetite trouble & $3(8.6)$ & $11(15.3)$ & 0.56 & n.s. \\
Sleep disorder & $2(5.7)$ & $22(30.6)$ & 7.07 & 0.005 \\
Headache & $2(5.7)$ & $14(19.4)$ & 2.77 & n.s. \\
Tiredness & $3(8.6)$ & $18(25)$ & 3.12 & n.s. \\
Nausea & - & $12(16.7)$ & 5.84 & 0.010 \\
Weakness & $1(2.9)$ & $12(16.7)$ & 3.53 & n.s. \\
Auto-inflicted injury & - & $1(1.4)$ & 0.43 & n.s. \\
Laxative use & - & $1(1.4)$ & 0.43 & n.s. \\
Forced vomiting & - & $2(2.8)$ & 0.87 & n.s. \\
Being hurt by stalker & - & $2(2.8)$ & 0.87 & n.s. \\
Panic attack & $2(5.7)$ & $15(20.8)$ & 3.78 & n.s. \\
\hline Emotional symptoms: & & & & \\
Suicidal thoughts & - & $4(5.6)$ & 1.779 & n.s. \\
Sadness & $7(20)$ & $36(50)$ & 6.83 & 0.008 \\
Anger & $14(40)$ & $47(65.3)$ & 3.78 & 0.044 \\
Confusion & $10(28.6)$ & $35(48.6)$ & 2.00 & n.s. \\
Fear & $2(5.7)$ & $33(45.8)$ & 15.28 & 0.000 \\
Aggressiveness & $5(14.3)$ & $18(25)$ & 0.96 & n.s. \\
Paranoia & $5(14.3)$ & $18(25)$ & 0.96 & n.s. \\
Irritation & $5(14.3)$ & $28(38.9)$ & 5.19 & 0.018 \\
Agoraphobia & $12(34.3)$ & $40(55.6)$ & 2.49 & n.s. \\
Lack of confidence in others & $1(2.9)$ & $5(6.9)$ & 0.53 & n.s. \\
\hline
\end{tabular}

Note: value between brackets in percentage; $\chi^{2}=$ chi-square; $p=p$-value; n.s. $=$ not statistically significant. The total percentage can score over 100 because each subject could choose more than one consequence.

The findings evidenced a higher level of consequences in the VCSLF group. In particular, concerning physical symptoms, the participants in the VCSLF group suffered from more sleep disorders and nausea. Concerning emotional symptoms, they suffered more sadness, anger, fear and paranoia than respondents in the VCS group.

\subsection{Depression and Anxiety Symptoms}

Overall, 133 participants (58.1\%) had a minimal score on depression symptoms, 35 (15.3\%) had a mild score, and $26(11.4 \%)$ had a moderate score, while 6 participants $(2.6 \%)$ had a score on the shortened Beck Depression Inventory (BDI) indicating a severe level of depression symptoms. The rest of the participants did not answer the majority of the items. In the case of anxiety symptoms, for the State Trait Anxiety Inventory (STAI)-Y1, 98 participants (42.8\%) scored below 40, which is the threshold value considered to be predictive of state anxiety symptoms. A total of $70(30.6 \%)$ participants scored a mild level of state anxiety; $33(14.4 \%)$ scored a moderate level, and $14(6.1 \%)$ scored a severe level of state anxiety. A total of 14 participants did not answer the items correctly (they indicated more than one answer). For the STAI-Y2, 88 participants (38.4\%) scored below 40; 79 (34.5\%) scored a mild level of trait anxiety; $40(17.5 \%)$ scored a moderate level, and 14 participants $(6.1 \%)$ scored a severe level of 
trait anxiety. Eight participants did not respond correctly to the questionnaire, indicating more than one response to the same items.

To analyse the impact of cyberstalking on victims, we compared NotVCS group $(n=122)$ with the VCSLF $(n=72)$ and VCS $(n=35)$ groups. A one-way ANOVA was performed, and the BDI, STAI-Y1 and STAI-Y2 scales were introduced as dependent variables (Table 3). Tukey post-hoc tests were performed.

Table 3. Depression and anxiety symptoms: comparison between subjects who had not experienced cyberstalking (NotVCS), victims of cyberstalking (VCS) and victims who had experienced cyberstalking and previous offline victimization in their lifetimes (VCSLF) (one-way ANOVA) $(N=229)$.

\begin{tabular}{|c|c|c|c|c|c|}
\hline & $\begin{array}{c}\text { NotVCS } \\
n=122(\%)\end{array}$ & $\begin{array}{c}\text { VCS } \\
n=35(\%)\end{array}$ & $\begin{array}{c}\text { VCSLF } \\
n=72(\%)\end{array}$ & $F$ & $p$ \\
\hline & $M(S D)$ & $M(S D)$ & $M(S D)$ & & \\
\hline $\begin{array}{l}\text { Depression symptoms } \\
\text { (Range: 0-15) }\end{array}$ & $3.03^{a}(3.349)$ & $3.84^{\mathrm{ab}}(3.751)$ & $5.30^{b}(5.040)$ & 6.13 & $<0.005$ \\
\hline $\begin{array}{l}\text { Anxiety symptoms-state inventory } \\
\text { (Range: } 20-80 \text { ) }\end{array}$ & 40.78 (11.692) & 38.97 (9.446) & 43.22 (10.992) & 0.83 & n.s. \\
\hline $\begin{array}{l}\text { Anxiety symptoms-trait inventory } \\
\text { (Range: } 20-80 \text { ) }\end{array}$ & $\begin{array}{c}41.77^{\mathrm{a}} \\
(10.856)\end{array}$ & $\begin{array}{l}41.18^{a b} \\
(10.131)\end{array}$ & $\begin{array}{l}45.39^{b} \\
(10.100)\end{array}$ & 1.52 & $<0.05$ \\
\hline
\end{tabular}

$M=$ mean; $S D=$ standard deviation; $F=$ Fisher's ratio; $p=p$ value; n.s. = not statistically significant. Significantly different means are indicated with different superscript letters.

The results emphasized that depressive symptoms and permanent anxiety symptoms (trait inventory) were significantly higher in the VCSLF group, with respect to those who were in the NotVCS group. No differences were found in the case of state anxiety symptoms.

\section{Discussion}

The aim of this study was to analyse the impact of cyberstalking, comparing victims of cyberstalking with victims of cyberstalking who had also experienced previous offline victimization in their lifetimes. Overall, our findings showed that the prevalence of cyberstalking was higher in our sample than in previous investigations. Whilst we found that more than $46 \%$ of the sample experienced cyberstalking, Paullet et al. (2009) found a victimization prevalence of one-third. An explanation could be found in the different gender composition of the sample, as we have an almost equal distribution of male and female participants. As suggested by Tjaden and Thoennes (2000), females are more prone to perceive themselves as victims, while men do not tend to perceive some intrusive behaviours as part of stalking (Sheridan et al. 2002; Yanowitz 2006). Furthermore, a possible explanation could be that the rates were higher because the thresholds for a label of cyberstalking were very low. Further research is needed to investigate in greater depth the gender differences in cyberstalking and to better understand the behaviours perceived as part of cyberstalking from a gender-specific point of view, using a clearer definition of what cyberstalking is and is not.

Among the behaviours that characterize cyberstalking, findings did not confirm those of the investigation by Cavezza and McEwan (2014) and Reyns et al. (2012), given that in our sample, most of the cyberstalkers were friends or acquaintances and not principally ex-intimate partners or strangers. Furthermore, our findings did not confirm the results of the D'Ovidio and Doyle (2003) investigation, as in our sample, most participants experienced more than one type of cyberstalking.

With regard to consequences, our findings supported those of previous investigations. In our sample, victims indicated higher scores for depression and anxiety than non-victims. In particular, victims of cyberstalking who had also experienced previous victimization in their lifetimes experienced more depression and symptoms of trait anxiety than victims of cyberstalking only and non-victims. These data shown that the lack of interventions for victims causes consequences that affect their quality of life. As noted by Jack et al. (2012), these consequences could become chronic and affect individuals' 
wellbeing and the quality of their social lives. The victims are at risk of experiencing a progressive distrust in others (see Davis et al. 1996), and many of the victims in this study who had experienced previous victimization were already manifesting signs of this tendency in terms of paranoia, fear, anger, and sadness. Moreover, as noted by Byrne and Senehi (2012), the ability to ask for help permits victims to understand how to cope with violent behaviours, decreases the risk of perpetuating a behavioural pattern that leads to a dysfunctional relationship, and leads to the recognition of potentially harmful relationships. Future investigations could consider the ability of victims to cope with stressful situations and the ways of suggesting different and more effective strategies.

This investigation has some limitations that must be considered. First, the majority of participants were university students who were residents of a region in north-western Italy. The sample may not have been entirely representative of the reference population, both in terms of educational level, residence and age. Moreover, we did not consider some important variables about the participants, such as gender and sexual orientation. Further research could be conducted on a wider sample of males and females in which information on sexual orientation is also collected. Such a study could allow for the investigation of lesbian, gay, bisexual, and transgender (LGBT) cyberstalking victims and the characteristics of cyberstalking, particularly in relation to the gender of the cyberstalker and the nature of the victim-perpetrator relationship. This information could be useful in understanding the role of acquaintances and strangers in the cyberstalking phenomenon related to sexual orientation. Finally, we did not consider the duration of cyberstalking, the coping strategies adopted and whether or not the victims reported (in this case, the motives) the cyberstalking to the police. The comparison of victims with those who had also experienced previous victimization could be useful in understanding the ability to ask for help.

Despite these limitations, the investigation suggests the importance of preventing cyberstalking and offering support to victims of cyberstalking. For example, it could be useful to prevent the phenomenon from occurring in cyberspace by offering strategies to stop unwanted online attention and intrusive behaviours. Reyns (2010) suggested the use of Situational Crime Prevention, whose purpose is "to reduce opportunities for crime by analysis and manipulation of the mechanisms which give rise to the specific crime" (p. 106), in order to limit cyberstalking. The program aimed to suggest strategies for coping with online harassment. These strategies are oriented towards increasing the effort (e.g., refusing to engage in communication when contacted online), increasing the risks for the cyberstalker to be identified (e.g., requiring a verification of identity before providing an email address), reducing the rewards (e.g., restricting social network page access to friends only), and removing excuses (e.g., reminders to potential cyberstalkers that harassment is not acceptable).

Moreover, easier methods of reporting cyberstalking, not only via phone but also via e-mail or online contact, could help victims report these experiences to the police. A description of the services offered by the police could be available in online environments, such as chat rooms and social networks, and could serve as a source of information for both victims and cyberstalkers. These recommendations do not mean that we suggest a more controlling presence by police in cyberspace; rather, we suggest a higher visibility of what the police could do to protect a victim of cyberstalking. Reporting to the police not only allows victims to intervene in the act of cyberstalking, but it also permits victims to recognize their victimization and their need for help. This recognition is the first strategy for decreasing an individual's discomfort and increasing collective security. With regard to intervention, it is crucial for victims to recognize their perception of vulnerability and to enhance their ability to defend themselves (Brown 2007). Finally, the support of a counsellor and/or a therapist could be important in recognizing the problem and increasing the ability of victims to cope, thus reducing distress and empowering victims with resilience (Iliffe and Steed 2000). These strategies could decrease the risk of a lack of confidence in others and social avoidance and isolation, which are feelings that characterize the victims of violent behaviours (Koss et al. 2017), such as cyberstalking victims. 


\section{Methods}

\subsection{Participants}

Participants were 229 students from the University of Torino, which is situated in a large city in the northwest of the country. The questionnaires were distributed to over 250 students; 21 (8.4\%) questionnaires were not fully completed. Respondents were almost equally distributed among females $(116,50.7 \%)$ and males, who were aged 18 to 27 years $(M=22.7, S D=2.31)$. With regard to marital status, the majority of participants were single $(140,61.1 \%), 70(30.6 \%)$ were engaged, $13(5.7 \%)$ indicated another type of engagement (such as "in the friend zone"), and 6 (3.5\%) were cohabiting. All respondents participated on a voluntary basis and did not receive any compensation or extra credit for their participation in the investigation.

\subsection{Measures}

\subsubsection{Cyberstalking}

The phenomenon was described in the questionnaire using the definition by Spitzberg and Hoobler (2002) and those on stalking by Galeazzi and Curci (2001): “Cyberstalking is a phenomenon that is defined as a set of threatening and/or harassing repeated behaviours aimed at searching, controlling, hacking personal information, and damaging an individual's reputation through the use of online communication tools: e-mail, blogs, social networks, chat rooms or other sites. Such undesirable behaviours are perceived by the victim as annoying, unwanted, threatening to their own safety". The scale developed by Reyns et al. (2012) was used to investigate the behaviours that characterized cyberstalking: contact ("Has anyone ever contacted you or attempted to contact you on more than one occasion online after you asked/told them to stop?", possible answers yes/no), harassment ("Has anyone ever persistently harassed or annoyed you or on more than one occasion online?", possible answers yes/no), unwanted sexual advances ("Has anyone ever made unwanted sexual advances toward you on more than one occasion online?", possible answers yes/no), threats of violence ("Has anyone ever spoken to you in a violent manner or threatened to physically harm you on more than one occasion online?", possible answers yes/no) and identity fraud ("Has anyone ever pretended to be you online, without your permission?", possible answers yes/no). For each behaviour, respondents were asked to answer whether or not they had experienced the behaviours and identify the nature of the victim-perpetrator relationship (possible answers: intimate partner, friend/acquaintance, stranger). Participants could indicate one or more than one behaviour (single or multiple victimization; e.g., only contact, contact and unwanted sexual advances). As suggested by Reyns et al. (2012), the cyberstalking victims were those who answered yes to at least one of the forms of cyberstalking behaviour. The questionnaire was adapted for use with an Italian audience by translating it from British English and then back-translating it (White and Elander 1992). The translation was performed by the authors and two research assistants and was matched to agreement in a final version.

\subsubsection{Consequences}

This measure was retrieved from the Italian (Acquadro Maran et al. 2014, 2017) version of the questionnaire constructed by the Network for Surviving Stalking (NSS) with Dr. Lorraine Sheridan (Forensic Psychologist, University of Leicester). It comprises one question about the physical consequences (12 items, yes/no answers; e.g., sleep disorder) and emotional consequences (11 items, yes/no answers; e.g., sadness).

\subsubsection{Depression and Anxiety Symptoms}

The shortened Beck Depression Inventory (BDI, Beck and Beck 1972) and the State Trait Anxiety Inventory (STAI, Spielberger 1988; Italian version by Pedrabissi and Santinello 1989) were used to investigate the psychological signs in victims as a consequence of cyberstalking. The scoring of the 
shortened BDI (13 items) permits the classification of no or minimal depression (scores 0-4), mild depression (5-7), moderate depression (8-15), and severe depression (>15) (in this study, Cronbach's $\alpha$ was 0.82 ). The STAI consists of two forms (Y1 and Y2; 20 items each) used for assessing how victims of cyberstalking feel "right now" at this moment (state inventory) and how they feel most of the time (trait inventory). Total scores can range between 20 and 80, and 40 is the threshold value considered to be predictive of anxiety symptoms. A rating scale defines the level of severity: from 40 to 50 is mild, 51 to 60 is moderate, $>60$ is severe. Cronbach's $\alpha$ for the two forms was 0.93 and 0.92 , respectively.

\subsubsection{Demographic Questions and Previous Victimization}

Participants were asked to indicate their gender, age, education, marital status, and time spent on social networks. They were also asked to indicate if, in their lifetime, they were victims of offline harassment or violence (In your lifetime, have you been a victim of physical or emotional violence?) experienced before their cyberstalking victimization, both as single and repeated episodes (e.g., sexual harassment, bullying).

\subsection{Procedure}

The data were collected by research assistants trained by the researchers. After the approval of the local ethical committee (NO. 277326/2017), each participant was given a printout of the questionnaire, the information letter, and the informed consent form in accordance with the Declaration of Helsinki. The questionnaires were administered to 250 students in classrooms before the beginning of a lesson, in the cafeterias and in dormitories. Participation in this study was voluntary. The questionnaires were returned immediately. Data were processed using the software IBM SPSS version 25 to produce mainly descriptive and inferential statistics. Descriptive measures (means $\pm S D$ ) were calculated for all test variables for each typology of victims (victims with or without previous victimization). $\chi^{2}$ tests were used to measure the differences between groups. One-way ANOVA was calculated to test the mean score differences in the BDI, STAI-Y1 and STAI-Y2 between groups. Differences were considered statistically significant if $p<0.05$.

Author Contributions: Conceptualization, d.a.m. and t.b.; formal analysis, t.b.; investigation, d.a.m. and t.b.; writing—original draft preparation, d.a.m.; writing—review and editing, d.a.m. and t.b.

Funding: This research received no external funding.

Conflicts of Interest: The authors declare no conflict of interest.

\section{References}

Acquadro Maran, Daniela, Antonella Varetto, and Massimo Zedda. 2014. Italian nurses' experience of stalking: A questionnaire survey. Violence and victims 29: 109-21. [CrossRef]

Acquadro Maran, Daniela, Antonella Varetto, Massimo Zedda, and Monica Franscini. 2017. Health care professionals as victims of stalking: Characteristics of the stalking campaign, consequences, and motivation in Italy. Journal of Interpersonal Violence 32: 2605-25. [CrossRef] [PubMed]

Acquadro Maran, Daniela, and Antonella Varetto. 2018. Psychological impact of stalking on male and female health care professional victims of stalking and domestic violence. Frontiers in Psychology 9: 321. [CrossRef] [PubMed]

Alexy, Eileen M., Ann W. Burgess, Timothy Baker, and Shirley A. Smoyak. 2005. Perceptions of cyberstalking among college students. Brief Treatment and Crisis Intervention 5: 279. [CrossRef]

Beck, Aaron T., and Roy W. Beck. 1972. Screening depressed patients in family practice: A rapid technic. Postgraduate Medicine 52: 81-85. [CrossRef] [PubMed]

Brown, Sandra L. 2007. Counseling Victims of Violence: A Handbook for Helping Professionals. Alameda: Hunter House. Byrne, Sean, and Jessica Senehi. 2012. Violence: Analysis, Intervention, and Prevention. Athens: Ohio University Press. Cassano, Giuseppe. 2017. Stalking, Atti Persecutori, Cyberbullismo e Tutela Dell'oblio [Stalking, Persecutory Behaviors, Cyberbullying and Oblivion]. Milan: Ipsoa. 
Cavezza, Cristina, and Troy E. McEwan. 2014. Cyberstalking versus off-line stalking in a forensic sample. Psychology, Crime E Law 20: 955-70.

Classen, Catherine C., Oxana Gronskaya Palesh, and Rashi Aggarwal. 2005. Sexual revictimization: A review of the empirical literature. Trauma, Violence, E Abuse 6: 103-29.

Davis, Robert C., Bruce Taylor, and Arthur J. Lurigio. 1996. Adjusting to criminal victimization: The correlates of postcrime distress. Violence and Victims 11: 21. [CrossRef] [PubMed]

De Fazio, Laura, and Chiara Sgarbi. 2012. Nuove prospettive di ricerca in materia di atti persecutori: Il fenomeno del cyberstalking [New research perspectives about stalking: The phenomenon of cyberstalking]. Rassegna Italiana di Criminologia 3: 146-59.

D'Ovidio, Robert, and James Doyle. 2003. A study on cyberstalking: Understanding investigative hurdles. FBI Law Enforcement Bulletin 72: 10.

Finn, Jerry. 2004. A survey of online harassment at a university campus. Journal of Interpersonal Violence 19: 468-83. [CrossRef]

Galeazzi, Gian Maria, and Paolo Curci. 2001. La sindrome del molestatore assillante (stalking): Una rassegna. Giornale Italiano di Psicopatologia 7: 434-52.

Golladay, Katelyn, and Kristy Holtfreter. 2017. The consequences of identity theft victimization: An examination of emotional and physical health outcomes. Victims $\mathcal{E}$ Offenders 12: 741-60.

Iliffe, Gillian, and Lyndall G. Steed. 2000. Exploring the counselor's experience of working with perpetrators and survivors of domestic violence. Journal of Interpersonal Violence 15: 393-412. [CrossRef]

Istat. 2016. Stalking Sulle Donne. Roma: ISTAT. Available online: https://www.istat.it/it/archivio/molestie (accessed on 15 October 2018).

Jack, Susan M., Marilyn Ford-Gilboe, C. Nadine Wathen, Danielle M. Davidov, Diane B. McNaughton, Jeffrey H. Coben, David L. Olds, and Harriet L. MacMillan. 2012. Development of a nurse home visitation intervention for intimate partner violence. BMC Health Services Research 12: 1952. [CrossRef] [PubMed]

Jansen van Rensburg, Shandré Kim. 2017. Unwanted attention: The psychological impact of cyberstalking on its survivors. Journal of Psychology in Africa 27: 273-76. [CrossRef]

Koss, Mary P., Jacquelyn W. White, and Elise C. Lopez. 2017. Victim voice in reenvisioning responses to sexual and physical violence nationally and internationally. American Psychologist 72: 1019. [CrossRef] [PubMed]

Kraft, Ellen, and Jinchang Wang. 2010. An exploratory study of the cyberbullying and cyberstalking experiences and factors related to victimization of students at a public liberal arts college. International Journal of Technoethics (IJT) 1: 74-91. [CrossRef]

Lyndon, Amy, Jennifer Bonds-Raacke, and Alyssa D. Cratty. 2011. College students' Facebook stalking of ex-partners. Cyberpsychology, Behavior, and Social Networking 14: 711-16. [CrossRef]

Macrì, Pasquale Giuseppe, Yasmin Abo Loha, Giorgio Gallino, Santiago Gascò, Claudio Manzari, Vincenzo Mastriani, Fabio Nestola, Sara Pezzuolo, and Giacomo Rotoli. 2012. Indagine conoscitiva sulla violenza verso il maschile [Survey on men victims of violence]. Rivista Di Criminologia, Vittimologia E Sicurezza 6: 30-47.

Marcum, Catherine D., George E. Higgins, and Jason Nicholson. 2017. I'm watching you: Cyberstalking behaviors of university students in romantic relationships. American Journal of Criminal Justice 42: 373-88. [CrossRef]

Marganski, Alison, and Lisa Melander. 2018. Intimate partner violence victimization in the cyber and real world: Examining the extent of cyber aggression experiences and its association with in-person dating violence. Journal of Interpersonal Violence 33: 1071-95. [CrossRef] [PubMed]

Manunza, Francesca, Vincenzo M. Mastronardi, and Monica Calderaro. 2018. Stalking of social healthcare workers: Preliminary results of a study conducted in Sardinia, Italy. Rivista di Psicopatologia Forense, Medicina Legale, Criminologia 23: 73-80. [CrossRef]

Oksanen, Atte, and Teo Keipi. 2013. Young people as victims of crime on the internet: A population-based study in Finland. Vulnerable Children and Youth Studies 8: 298-309. [CrossRef]

Paullet, Karen L., Daniel R. Rota, and Thomas T. Swan. 2009. Cyberstalking: An exploratory study of students at a mid-Atlantic university. Issues in Information Systems 10: 640-49.

Pedrabissi, L., and M. Santinello. 1989. Inventario Per L'ansia di «Stato» e di «Tratto»: Nuova Versione Italiana Dello STAI Forma Y: Manuale. Firenze: Organizzazioni Speciali, pp. 1-44. 
Reed, Margaret E., Linda L. Collinsworth, Angela K. Lawson, and Louise F. Fitzgerald. 2016. The psychological impact of previous victimization: Examining the "Abuse defense" in a sample of harassment litigants. Psychological Injury and Law 9: 230-40. [CrossRef]

Reyns, Bradford W. 2010. A situational crime prevention approach to cyberstalking victimization: Preventive tactics for Internet users and online place managers. Crime Prevention and Community Safety 12: 99-118. [CrossRef]

Reyns, Bradford W., Billy Henson, and Bonnie S. Fisher. 2012. Stalking in the twilight zone: Extent of cyberstalking victimization and offending among college students. Deviant Behavior 33: 1-25. [CrossRef]

Sheridan, Lorraine, Raphael Gillett, and Graham Davies. 2002. Perceptions and prevalence of stalking in a male sample. Psychology, Crime and Law 8: 289-310. [CrossRef]

Sheridan, Lorraine P., and Tim Grant. 2007. Is cyberstalking different? Psychology, Crime E Law 13: 627-40.

Spielberger, Charles D. 1988. State-Trait Anxiety Inventory. Hoboken: John Wiley \& Sons, Inc.

Spitzberg, Brian H., and Gregory Hoobler. 2002. Cyberstalking and the technologies of interpersonal terrorism. New Media \& Society 4: 71-92.

Strawhun, Jenna, Natasha Adams, and Matthew T. Huss. 2013. The assessment of cyberstalking: An expanded examination including social networking, attachment, jealousy, and anger in relation to violence and abuse. Violence and Victims 28: 715-30. [CrossRef] [PubMed]

Tjaden, Patricia, and Nancy Thoennes. 2000. Prevalence and consequences of male-to-female and female-to-male intimate partner violence as measured by the National Violence Against Women Survey. Violence Against Women 6: 142-61. [CrossRef]

Westrup, Darrah. 1998. Applying functional analysis to stalking behavior. In The Psychology of Stalking. San Diego: Academic Press, pp. 275-94.

White, Marjorie, and Gunnel Elander. 1992. Translation of an instrument: The US-Nordic Family Dynamics Nursing Research Project. Scandinavian Journal of Caring Sciences 6: 161-64. [CrossRef]

Worsley, Joanne D., Jacqueline M. Wheatcroft, Emma Short, and Rhiannon Corcoran. 2017. Victims' Voices: Understanding the Emotional Impact of Cyberstalking and Individuals' Coping Responses. Sage Open 7: 2158244017710292. [CrossRef]

Wright, Michelle F. 2018. Cyberstalking victimization, depression, and academic performance: The role of perceived social support from parents. Cyberpsychology, Behavior, and Social Networking 21: 110-16. [CrossRef] [PubMed]

Yanowitz, Karen L. 2006. Influence of gender and experience on college students' stalking schemas. Violence and Victims 21: 91. [CrossRef]

(C) 2019 by the authors. Licensee MDPI, Basel, Switzerland. This article is an open access article distributed under the terms and conditions of the Creative Commons Attribution (CC BY) license (http://creativecommons.org/licenses/by/4.0/). 